\title{
BIQQi-BYWORD
}

Proceedings of Anticancer Research

\section{Clinicopathological Features of Simple Primary Squamous Cell}

\section{Carcinoma of Breast}

\author{
Wei Yuxian Li Fan Kong Lingquan* \\ The First Affiliated Hospital of Chongqing Medical University, Chongqing 400016, China
}

\section{ARTICLE INFO}

Article history:

Published online: 15th July, 2017

Key words:

Breast cancer

Primary squamous cell carcinoma

Chemotherapy of primary cancer

\section{ABSTRACT}

Objective: To investigate the clinicopathological features and prognosis of primary squamous cell carcinoma of the breast. Methods: 2 cases of primary squamous cell carcinoma of the breast were analyzed. According to the TNM stage of breast cancer, the patients underwent hematectomy and stage IV and stage II. All the patients were treated with radiotherapy. Results: The age of onset was younger, ER / PR was negative, and 4 months after operation, no recurrence or distant metastasis was found. Conclusion: The clinical features of primary squamous cell carcinoma lack specificity, misdiagnosis, need to pay attention to differential diagnosis, standardized diagnosis and treatment strategy still need further study.

\section{Introduction}

Breast primary squamous cell carcinoma (referred to as squamous cell carcinoma) is a metaplastic breast cancer, clinical is extremely rare, domestic occasional reports. Compared with other types of breast cancer, breast primary squamous cell carcinoma in the clinical manifestations of the rapid increase in the cystic

*Corresponding author:

Kong Lingquan, Department of Endocrine Breast Surgery, First Affiliated Hospital, Chongqing Medical University, 400016, China. Email: huihuikp@163.com or solid mass, may be associated with local skin redness, less ipsilateral axillary lymph node metastasis. Mammography and molybdenum target radiography and other imaging specificity are poor, easy to delay the diagnosis and even cause misdiagnosis and mistreatment. In view of the clinical characteristics of the disease, there is no uniform and clear standardized treatment and prognosis evaluation criteria. In 
this study, we analyzed the clinical and pathological characteristics of 2 cases of primary squamous cell carcinoma of the breast in 2016, combined with literature review, hoping to accumulate the experience of clinical diagnosis and treatment, and provide a new diagnosis and treatment strategy in order to improve the prognosis of patients.

\section{Method}

Retrospective analysis of 2016 years 1 - 11th month. My department has a total of 1004 cases of breast cancer surgery patients, including postoperative pathological diagnosis of breast squamous cell carcinoma in 2 cases, accounting for $0.2 \%$. Collect patient clinical data for summary analysis (see Table 1).

\section{Results}

Clinical stage IV in the mass resection after systemic PET-CT examination found no other parts of the lesion. 2 patients underwent total mastectomy $+/$ - axillary lymph node dissection, postoperative immunohistochemical results were ER / PR (-), respectively, to TP and TEC program chemotherapy 6 courses, more than $5 \mathrm{~cm}$ lumps were accepted after surgery Assisted radiotherapy 25 times, 2 patients were not endocrine therapy, regular follow-up after surgery. 4 months after the end of chemotherapy, liver, lung, bone examination was not found in local recurrence of lesions and distant metastases, short-term prognosis is acceptable, to be further follow-up data.

\section{Discussion}

Among the reported breast squamous cell carcinoma, the majority of patients aged $42-79$ years old, the disease is very rare, accounting for $0.7-6 \%$ of breast cancer; the incidence of breast cancer in pregnancy is lower, every 100,000 cases of childbirth There are 1040 cases of breast cancer, breast cancer in the first trimester of pregnancy is rarer, only occasionally reported at home and abroad ${ }^{[1]}$. The first patient reported in this article is only 25 years old, in breastfeeding, is by far the youngest breast cancer patients, very rare.

Most experts believe that breast squamous cell carcinoma is metaplastic cancer, its tissue source is not clear. Breast squamous cell carcinoma are having two theories: a theory that the mammary duct epithelium in the stimulation of estrogen metaplasia of squamous epithelium or cells; another theory that during embryonic development of ectodermal retraction tissue development was misleading after skin coverage and other factors make the breast squamous cell carcinoma ${ }^{[2]}$.

Breast lumps are mostly located in the outer quadrant, with cystic solid or solid mass as the main manifestation, usually lumps grow rapidly, can invade the skin, axillary lymph node metastasis is rare. Combined with clinical examination and mammography and molybdenum target radiography and other imaging studies, for the solid mass of the main manifestations of breast squamous cell carcinoma can be considered the initial diagnosis of breast cancer, but if the cystic solid occupying as the main performance of patients It is easy to confuse with breast cysts or abscess and misdiagnosed. Histopathological diagnosis can diagnose breast squamous cell carcinoma, for the solid mass can choose hollow needle puncture, and cystic solid mass is required to resection biopsy, but some well-differentiated squamous cell carcinoma, only hollow needle puncture and

Table 1 Cases of breast cancer cases of clinical data

\begin{tabular}{|c|c|c|c|c|c|c|c|c|c|}
\hline Case & $\begin{array}{l}\text { Age } \\
\text { (Years) }\end{array}$ & $\begin{array}{l}\text { Major clinical } \\
\text { manifestations }\end{array}$ & $\begin{array}{l}\text { Tumor } \\
\text { Longest } \\
\text { diameter } \\
(\mathrm{cm})\end{array}$ & $\begin{array}{l}\text { Clinical } \\
\text { staging } \\
(\mathrm{TNM})\end{array}$ & $\begin{array}{l}\text { Imaging } \\
\text { findings }\end{array}$ & $\begin{array}{l}\text { Diagnostic } \\
\text { methods }\end{array}$ & $\begin{array}{l}\text { Surgical } \\
\text { methods }\end{array}$ & $\begin{array}{l}\text { Immunohistochemical } \\
\text { results }\end{array}$ & $\begin{array}{l}\text { Adjuvant } \\
\text { therapy }\end{array}$ \\
\hline 01 & 25 & $\begin{array}{l}\text { Rapid increase } \\
\text { in cystic solid } \\
\text { Pack with local } \\
\text { skin redness }\end{array}$ & 9.7 & IV & $\begin{array}{l}\text { Ultrasound } \\
\text { can be seen } \\
\text { huge } \\
\text { cystic solid } \\
\text { place }\end{array}$ & $\begin{array}{l}\text { Lump } \\
\text { resection }\end{array}$ & $\begin{array}{l}\text { Improved } \\
\text { radical } \\
\text { surgery }\end{array}$ & ER-/PR-/HER-2 & $\begin{array}{l}\text { chemotherapy } \\
+ \text { radiotherapy }\end{array}$ \\
\hline 02 & 46 & Solid mass & 3.0 & II & $\begin{array}{l}\text { ultrasound } \\
\text { and molyb- } \\
\text { denum target } \\
\text { can be seen } \\
\text { solid place }\end{array}$ & $\begin{array}{l}\text { Hollow } \\
\text { needle } \\
\text { aspiration }\end{array}$ & $\begin{array}{l}\text { Full mas- } \\
\text { tectomy } \\
\text { +Sentinel } \\
\text { lymph node } \\
\text { biopsy }\end{array}$ & +ER-/PR-/HER-2 & chemotherapy \\
\hline
\end{tabular}


even rapid frozen pathology still difficult to diagnose, often need paraffin-embedded histological examination and immunohistochemistry to further clarify. Pathological results can be high, moderate and low differentiation squamous cell carcinoma, immunohistochemical results for the ER (-), PR (-), HER-2 (-), CK (+) ${ }^{[3]}$. Combined with the literature to explore the diagnosis of breast squamous cell carcinoma to meet the following criteria: (1) Breast parenchymal squamous cell carcinoma components in more than $90 \%$; (2) The excision of primary breast cancer skin; (3) Excluding other parts of the transfer squamous cell carcinoma. It can be seen that breast primary squamous cell carcinoma for the exclusion of diagnosis, with other types of primary breast cancer and metastatic cancer phase identification. Combined with these two patients, the first case in the mass resection after the improvement of PET-CT examination found no other parts of the lesion, the second case in the chest before surgery and abdomen ultrasound examination did not find other parts of the lesion. In order to confirm the diagnosis, the conditions permit should be done as soon as possible after the esophagus, nasopharynx, oral, pulmonary, ovarian and other parts of the examination to exclude the transfer elsewhere, but ultimately still histopathological and immunohistochemical diagnosis.

Breast squamous cell carcinoma treatment with invasive breast cancer, mostly surgical treatment, supplemented by chemotherapy and radiotherapy, not recommended endocrine therapy and targeted therapy ${ }^{[4]}$. Surgical treatment and more to improve the radical surgery, whether the need for axillary lymph node dissection is still controversial. Although the majority of patients with clinical examination and cannot palpable axillary lymph node metastasis, but as an assessment of follow-up treatment and prognosis of the important factors, the proposed line ipsilateral axillary lymph node dissection. Wargotz et al ${ }^{[5]}$ reported 22 cases of breast squamous cell carcinoma, of which 2 cases of axillary lymph node metastasis, 5 cases over axillary lymph node metastasis in other parts. Chemotherapy options are different, as a postoperative adjuvant therapy, anthracycline can be combined with taxane or a platinum-based combination of chemotherapy, the current majority of recommended platinum-based program. Tsung et al ${ }^{[6]}$ found that breast primary squamous cell carcinoma of anthracycline combined with taxane chemotherapy is not sensitive to radiotherapy is not sensitive to cisplatin-based chemotherapy is effective. But most experts believe that should still be based on the size of the primary tumor and axillary lymph nodes to decide whether to accept radiotherapy.

The overall prognosis of primary squamous cell carcinoma of the breast was poor, and most patients did not find local recurrence and distant metastasis in the short-term follow-up, but were found to be more distant from the lungs during long-term follow-up ${ }^{[7]}$, and follow- up which should be focused on. Rokutanda et al stated ${ }^{[8]}$ that the primary malignant squamous cell carcinoma of the malignant degree is higher, even if the early clinical manifestations of axillary lymph node metastasis, but within 1 year after the occurrence of lung metastasis. Less than 40 years of age and tumor diameter of more than $3 \mathrm{~cm}$ usually suggest poor prognosis, the early absence of local recurrence or distant metastasis 5-year survival rate can be more than $80 \%{ }^{[9]}$. Limited to the rare disease, clinical reports, few cases and scattered, standardized diagnosis and treatment programs and strategies still need further study to improve the prognosis of patients.

\section{References;}

[1] Mehta A, Staler H, Saleem A, et al. Breast Cancer in Pregnancy-Enough Vigilance? [J]. Obstet Gynaecol, 2014, 22: 1 .

[2] Lee ES, Lundberg (TM), Rose JF, et al. Special Issue Surgical Oncology A Retrospective Case Series and Literature Review of Primary Squamous Cell Cancer of the Breast [J]. Surgery, 2014, S2 (4).

[3] Kawaguchi K, Shin SJ. Immunohistochemical Staining Characteristics of Low-Grade Adenosquamous Carcinoma of the Breast [J]. Am J Surg Pathol, 2012, 36 (7): 10091020 .

[4] Gupta N, Vashisht R, Nimbran V, et al. Primary Squamous Cell Carcinoma of the Breast: Case Report and Management Decisions [J]. J Cancer Res Ther, 2012, 8: 323325 .

[5] Wargotz ES, Norris HJ. Metaplastic Carcinomas of the Breast. IV. Squamous Cell Carcinoma of Ductal Origin [J]. Cancer, 1990, 65 (2): 272-276.

[6] Tsung SH. Primary Pure Squamous Cell Carcinoma of the Breast Might Be Sensitive to Cisplatin-Based Chemotherapy. Case Rep Oncol 2012,5: 561-565.

[7] Nayak A, Wu Y, Gilerease MZ. Primary Squamous Cell Carcinoma of the Breast: Predictors of Locoregional Recurrence and Overall Survival [J]. Am J Surg Pathol, 2013,37: 867-873.

[8] Rokutanda N, Lino Y, Yokoe T, et al. Primary Squamous Cell Carcinoma of the Breast During Lactation: A Case Report [J]. Jpn J Clin Oncol, 2000, 30 (6): 279-282.

[9] Sheela CS, Ramakant P, Shah G, et al. Primary Squamous Cell Carcinoma Of The Breast Presenting As A Cystic Mass [J]. J Postgrad Med, 2013, 59: 155-156. 